\title{
'Mothers at the Malls': A Study of Glocal Aspirations and Mothering from Delhi
}

\author{
Ridhima Tewari ${ }^{1 *}$, Manjeet Bhatia ${ }^{2}$
}

Published: September 10, 2019

\begin{abstract}
This paper utilises findings from a short-term project titled Mall: $A$ Gendered Space, undertaken by the Women's Studies and Development Centre (WSDC), University of Delhi, India, between 2016 and 2017. The project was aimed at examining the way newly-created, globalised spaces such as shopping malls (in this case a bustling mall frequented by different classes in upscale Delhi) are being accessed by women in India. Investigations into the Promenade Mall involved interaction with women accessing the space in two primary capacities: migrant women that constituted the majority of the mall workforce, and women visiting the mall as the predominant category of consumers. Women from different social classes appeared to have diversely adapted glocal shifts and practices typified by shopping mall use. While the migrant women employed there as security-personnel, or as housekeeping staff, took from it an aspirational framework of urban-living, employment, and education, the middle, upper-middle, and upper class woman as consumers appreciated and imbibed a self-development project of consumption and transformation (that included selfcare, grooming and additional consumer practices). This article employs findings from the WSDC project on shopping malls to establish how processes of mothering in case of women-women workers of the Mall, as well mothers visiting the Mall as consumers, drew heavily from their exposure to the apparently emboldening forces of globalisation, while simultaneously resulting in further entrapment for these women through the very aspirational mother-functions they seemed to perform. Furthermore, such mothering practices exemplified why motherhood and its interconnections with materiality and consumption in varied forms, and with class dynamics, are indispensable to any critical understanding of women's lives today.
\end{abstract}

Keywords: aspiration, consumption, mothering, materiality, shopping malls

\section{INTRODUCTION}

Whilst 'malls' or 'shopping malls' were first anticipated globally in the form of super stores or mega stores in early twentieth century USA (1907 onwards) in places such as Baltimore, California, Kansas City (Singh and Srinivasan, 2012), shopping malls in India emerged only in the late 1990s and the early 2000s. Their emergence and rapid spread in India has been widely interlinked with the market liberalisation policy adopted by the country in the 1990s, which included a relaxation in foreign direct investment (FDI) up to 51\% in joint ventures in 2006 (Singh and Srinivasan, 2012). The subsequent boom in modern retail in the country has also significantly impacted its cultural and social institutions. In fact, the synthesising of material and cultural forces in urban, and semi-urban lifestyles has been acknowledged as a major goal of retail giants in post-globalisation India. In a book titled $I t$ Happened in India (2007), published quite early in India's economic trajectory of consumer-culture and retail expansion, Dipayan Baishya records clear goals of the retail icon Kishore Biyani, CEO, Future Group, India, who started out in the 1990s with the aim of conquering 'the entire Indian consumption space' (Biyani and Baishya, 2007). Biyani's group inaugurated some of the earliest 'super stores' in India, encompassing different aspects of consumer needs and aspirations - from clothes, to furniture, to food items, and even insurance. More importantly, Biyani's conceptualising of these giant stores (such as Pantaloons, Big Bazaar, Central owned by the Future group), or shopping malls, implicated consumption practices by social units particularly the family in the expanding retail business of the country. Biyani was of the view that malls served a purpose explicitly beyond shopping, catering also to the need for a clean, sanitised, safe and commercial space where families would get together (Biyani and 
Baishya, 2007). From the perspective of analysing employment, self-perception and furthering of 'neoliberal governmentality' through malls (and the retail industry in general), Nandini Gooptu's research provides insights into the way work in malls contributed to an ethos of self-dependence, hard work and an apparently apolitical agenda of self-growth, delinked from policy interventions/expectations from a minimised State. Gooptu saw this as a further step in the production of compliant workers who would carry forward a new work culture, necessary for forwarding the agenda of the corporate sector, in post globalisation India (Gooptu, 2009). Today, more than a decade after corporates such as Biyani conceived their retail arenas as a site of familial 'togetherness', and the young mall worker began her/his attempts at self-growth, the Mall has established itself as a critical 'place' of socialisation, aspiration and class-interaction, and is not merely a consumer 'space'.

\section{METHODOLOGY, SCOPE AND AIMS OF THE STUDY}

In his writing, French Marxist Pierre Bourdieu seeks to do away with what he calls a set of 'meaningless oppositions' that exist in sociological research, such as those of the conceptual and empirical, microsocial and macrosocial, and theory and methodology (Bourdieu, 1996: 8). These 'oppositions', the French sociologist says, are especially inseparable for examining 'notions of social space, symbolic space, or social class', that are best captured through 'a discursive montage' of photographs, interview excerpts, statistical tables, as well as abstract language blended with the most concrete of records (Bourdieu, 1996: 7-8). In a similar spirit of attempting to examine malls as both social and symbolic spaces of intersecting social classes, the WSDC undertook a research study of a popular mall in the heart of India's capital, Delhi, during 2016-17. Additionally, the study was also intended to investigate malls as globalised spaces catering to the complex material needs of a large regional chunk of urban and semi-urban population near the city. The fieldwork for the study included collection of data through vox-populi, semi-structured interviews (about 60 interviews of diverse participants interacting with the mall), focus group discussions, and collection of photographic images and video clips, which were all subsequently analysed. The project involved ethnographic study of the Promenade Mall population conducted over a period of six months.

At the outset, it is crucial to delineate the parameters of the study. Limitations of time, resources and other logistics meant that the team undertook the fieldwork over a limited period of about six months. The study did not extend to a comparative analysis of different shopping malls within Delhi, or to a comparison of patterns of consumption, mothering and lifestyle shifts across different timelines. There were also limitations to the time that the staff of the Mall could provide for group discussions and interviews, with defined shifts of work and shortened breaks. Prolonged interviews with consumers visiting the Promenade Mall were difficult to obtain due to the leisured nature of shopping practices. It is also important to acknowledge debates existing in relation to the ethnographic method itself, the 'objective' role of the researcher in collecting data on the researched, challenges which Bourdieu broadly terms as 'objective limits of objectivism' (Bourdieu, 1977: 1). Besides delineating the limits of objectivity as early as the 1970s, Bourdieu speaks of the need to study 'the dialectical relations between the objective structures to which the objectivist mode of knowledge gives access and the structured dispositions within which those structures are actualized and which tend to reproduce them', a project Bourdieu remained committed to, through dissecting concepts such as 'habitus', 'field' and 'social class' (3). The debate on the ethnographic 'method', and the problematics of 'observations', is an ongoing one, and has been addressed in recent decades through the notion of 'intersubjectivity'- a term found in the philosophical postulations of Edmund Husserl, who employed it to suggest our "worlds of experience" though separated, "in fact become joined by concatenation of actual experience to make up the one intersubjective world" (Husserl, 1983: 108). Intersubjectivity, in anthropological discourse, has come to denote the complex relationship shared by the researcher(s) and the researched in the field, acknowledging the challenges of objective ethnography, and the presence of multiple subjects. In the context of Indian anthropology, multiple attempts have been undertaken to defend/understand/redefine the task of the researcher, such as explained in Meenakshi Thapan's analysis of the anthropological method, where Thapan asserts:

...the constitution of the ethnographic text is always never a complete statement or absolute truth but only a fragment of understanding social reality, a contribution towards a deeper understanding of the whole, a movement towards an intersubjective understanding of social relations in everyday life. (Thapan, 1996: 2631).

The fieldwork for the Mall project was undertaken with a similar desire to contribute to a fraction or snapshot of a possible 'whole', while understanding that language, 'observation', and even accessing of the Mall space by academic researchers and subjects of particular social classes were complex elements that played out simultaneously in the field. The WSDC faculty and student-researchers undertook the study at DLF Promenade Mall, Vasant 
Kunj, Delhi. The researchers interacted with Mall visitors across different age groups and gender, and with Mall staff across social hierarchies: from the Mall management to various teams on the ground (such as housekeeping and security teams). The families of some of the migrant housekeeping and security personnel were also interviewed. Lastly, the research team also conducted field trips to urban villages in the Promenade Mall's vicinity for studying the mall's inside/outside realities and the emergent socio-spatial dichotomies.

Considerable research has shed light on how the post-globalisation world is steeped in practices of consumption and lifestyle shifts, which are created by, and in turn propel, the liberalised markets globally. Since the 1970s, cultural theorists from Roland Barthes to Pierre Bourdieu have analysed consumer choices, goods and lifestyle practices in popular culture, to underline the centrality of the 'material' in shaping power-relations. Toril Moi in an essay assessing Bourdieu's contributions speaks of the critic's micro-theoretical approach, which enables Bourdieu 'to incorporate the most mundane details of everyday life ..., -make sociological theory out of everything' (Moi, 1991: 1019-1020). Bourdieu investigates 'high' and 'low' elements of social classifications, unravelling how power is constituted and retained by a set of practices that define one's position in a particular social order. It is here that the notion of physical space as 'social space' also becomes important. Returning to Bourdieu's essay 'Physical Space...', the critical thinker underlines how a physical space shares its features with what he terms 'social space', stating:

There is no space, in a hierarchical society, which is not hierarchized and which does not express social hierarchies and distances in a more or less distorted or euphemized fashion, especially through the effect of naturalization attendant on the durable inscription of social realities onto and in the physical world...(11)

It is in this sense that the shopping mall becomes a social space that endorses and upholds the social logic of consumption, taste, cultural capital, and consequently, new hierarchies.

Contemporary studies on materiality, social systems and consumption have found shopping malls to be pivotal sites of social stratification and even marginalisation. Malcom Voyce (2007), has argued that these quasi-public spaces by the very virtue of the commodities they engage with, the technologies they use and their spatial exclusivity, promote 'dividing practices' typical of neoliberal systems of power. Malls, according to Voyce, provide access and privileges only to the 'rightful spending middle class subjects, ironically, even before they set foot inside the mall space for the first time' (Voyce, 2007: 2055). A further category of complexity and stratification emerges with the introduction of women as the dominant group occupying commercial spaces such as shopping malls. The presence of women as the predominant category of consumers in shopping malls is well-established (Craig Martin, et al. 2007; Taylor and Cosenza, 2002). In contrast, available research on women and their interaction with globalised spaces such as shopping malls in India is scant, though considerable literature does address issues of women's mobility, particularly in urban and semi-urban locales (Kalpana, 2002; Shilpa Phadke et al., 2011).

The Promenade Mall research study undertaken by WSDC was an attempt to fill such existing gaps in the study of women's mobility (social and physical), shifts in patterns of consumption, and their conscious/unconscious negotiations of socio-economic forces in a post-globalised world. The project, Mall: A Gendered Space was conducted at a mall that captured consumers from what is now fashionably described as the new middle class in India. The DLF Promenade is located in South Delhi, in the upscale locality of Vasant Kunj. The Promenade Mall is close to the international airport of Delhi, as well as to some well-known educational institutions of the national capital. More importantly, the Promenade Mall is embedded in the midst of two distinct yet interconnected malls: the DLF Emporio on its left (housing luxury brands such as Gucci, Louis Vitton, Jimmy Choo, Armani), and on its right the Ambience Mall (known for its reasonably priced brands like Pantaloons, Westside, and Shoppers Stop, and a food court). The Promenade Mall serves as a spatial, as well as budgetary 'middle-ground' between the elite clientele and amenities of the Emporio and the popular and the pocket-friendly Ambience Mall. It boasts of a blend of imported/designer brands, along with Indian retail labels, which while not always affordable, offer a variety of choices to the consumer. The Senior Manager (Operations) of the Promenade Mall described this factor as primarily responsible for the niche that the Promenade Mall has carved out for itself, attracting consumers from the middle and upper middle classes of Delhi. He also shared that $90 \%$ of consumers of the Promenade Mall were women. The WSDC research team was able to interview a number of women visitors, and observed the large presence of mother-daughter pairs, as well as of new mothers with infants. $60 \%$ of the visitors to the DLF Promenade who we asked, were regular mall visitors. In terms of age brackets, the manager shared his data that $50 \%$ of mall-goers were between the ages of $15-24$ years, $40 \%$ in the bracket of $25-40$ years, and the rest, $10 \%$ were over 40 years of age. The mall management took cognisance of the gender and age stratifications of mall visitors, and selected and shuffled its brands and amenities accordingly. Though the Manager repeatedly stressed that malls were 'destinations' of socialising, relaxation, shopping and entertainment for all, he revealed that shopping and purchase of goods in the Promenade Mall was mainly done by the $10 \%$ of shoppers of over 40 years of age. Keeping in mind that $90 \%$ of consumers at the Mall were women, the Mall management had organised 
$90 \%$ of its retail brands and lifestyle arenas (such as a nail-art studio, spa, play-arena for kids) for targeting its women consumers. Each floor of the Promenade Mall had an architectural layout that ensured each mallgoer would compulsorily have to negotiate multiple brand stores and outlets, before she/he could arrive at any specific 'destination' within it. Security and upkeep of the Promenade Mall premises were two other aspects that emerged as critical priorities of the mall management. The Manager of Operations compared the security blanket provided at the Promenade Mall to that provided at international airports, and reaffirmed the fact the mall was a safe, and fully surveilled space. The ancillary team responsible for the functioning of the Promenade Mall consisted of 500600 employees, and included a security team and a housekeeping team (apart from specific teams for event planning, advertising and so on). The Manager stated that about $90 \%$ of the mall employees were in fact migrants coming to the capital Delhi for employment opportunities.

This article attempts to analyse women shopper's presence in newly-created globalised spaces such as shopping malls, and highlights important strands pertaining to women's role as consumers in contemporary nations such as India. Additionally, the paper will interlink women's patterns of consumption and lifestyle preferences with the neoliberal aims of the retail market (Biyani and Baishya, 2007), which sought to transform familial practices, lifestyle choices, and socialisation mechanisms through women's own performance of 'mothering' and shopping. Motherhood and practices of mothering emerged as both the sites as well as forces of change in social fields, symbolised by the Promenade Mall. Issues of exclusion and stratification (as discussed by Voyce, 2007), with regard to the constitution, operation and marketing strategies of the Promenade Mall are addressed by incorporating into the study the participation of the Mall workforce, which challenges any easy categorising of what the Mall experience symbolises. Overall, the scope of the paper involves a study of mothering with regard to the women accessing the Mall as consumers (primarily from the middle and upper middle classes), and as security and housekeeping personnel (majority being migrant workers seeking employment and financial security) to understand how the aspirational project of lifestyle shifts and upward mobility are both shaped and realised with exposure to the Promenade Mall. The emergent practices of mothering are thus complex, further implicating women in the project of neoliberal consumption and what may be controversially described as gendered 'empowerment'.

\section{MOTHERHOOD, MATERIALITY AND 'FIELD'}

The discourse around motherhood in India has seen important contributions from scholars such as Samita Sen (1993). Sen undertakes a sustained analysis of the socio-cultural demands made on women historically, through the mother-function they have been expected to perform. In essays such as 'Motherhood and Mothercraft: Gender and Nationalism in Bengal' (with specific reference to $19^{\text {th }}$ and early $20^{\text {th }}$ century Bengal), Sen not only demystifies the 'general valorisation of motherhood', but also examines the ways in which issues of lack of social welfare policies and support - such as medical aid for infant mortality and maternal care - were collapsed into an ideological critique of 'careless' and 'neglectful' mothers (1993: 231-234). Similarly, with regard to the domain of workplace, employment and construction of motherhood, Sen's later essay (2008) points to recurrent attempts at 'resolving' the women's question at work, by viewing women primarily as mothers rather than professionals, with many people at the time putting forward claims of the adverse effect work was having on processes of mothering and housewifery (2008: 82).

Globally, the field of Motherhood Studies has grown. Samira Kawash (2011) notes challenges that the field currently faces-from fundamental questions regarding motherhood and its alignment with an essentially 'feminist' cause, to constant linking of motherhood with the project of familial values, to challenges offered by the emergence of post-structuralist thinking, and the reluctance to factor in issues of materiality and market in understanding motherhood (2011: 972). Kawash highlights the contribution of Andrea O'Reilly (2010), whose work appears to address some of the debates noted above, by explicating feminist underpinnings of motherhood studies, and interconnecting academic studies with the lived experiences of mothers. O'Reilly (2010: 4), describes the field of motherhood studies as a 'new and exciting discipline', that is shaped, and in turn shapes various forces of the new millennium. O'Reilly's book studies phenomena as varied as 'globalization, raising trans children, HIV/AIDS, the new reproductive technologies, queer parenting, the motherhood memoir, mothering and work, welfare reform, intensive mothering, mothers and/in politics, the influence of the Internet', among others, to investigate motherhood and its dynamic interface with the material and cultural (2010: 3-4). In recent years, materiality has emerged as central to cultural discourse. In the 'Introduction' to the book Materiality (2005), Daniel Miller sets out to unpack contemporary underpinnings of the 'material', locating material culture itself within wider 'conceptualizations of culture'. Miller uses a two-pronged approach to exemplify the 'material': (1) of 'theory of objects as artefacts' - as exemplified by Bourdieu's (1977) understanding of objects, their order, and positioning, as fundamental to our understanding of the world around us, and (2) of a Hegelian (1977) rejection of distinction between 'humanity' and 'materiality', asserting, 'we both produce and are the products of these historical processes' (Miller, 2005: 9). Mothering and consumption are both dependent on and contextualised by artefacts we create, as 
well as 'artefacts' themselves that are in a complex interactive relationships with technologies, spaces, goods and capital of various kind.

Issues of material consumption, marketing, and doing motherhood, have also gradually ascended to the forefront of motherhood discourse. In their research article Sara Afflerback et al. (2014) assert how materiality is of singular importance to the constitution of motherhood for the majority of middle class American women:

(...) acquisition of consumer goods is a significant aspect of the transition to motherhood in contemporary US society, used both for the practical care of the baby and as a symbolic marker of the woman's new status as a mother... this acquisition and arrangement of consumer goods occurs in ritualized fashion. We suggest that two prevalent rituals of motherhood—nesting, or creating a physical space for the baby to inhabit, and gifting, which typically takes place through events such as baby showers-are in fact "consumption rituals." By understanding them as such, we see how consumption is critical to women during the transition to motherhood...It also provides insight into the role consumption plays in perpetuating the gender system, in terms of gendering the child and reinforcing the culture of motherhood (2014: 2).

Such approaches to consumption move forward from the one-dimensional model of consuming 'goods', to a study of the complex interlinks between such goods and modern myths, performances, and rituals built around them (Barthes, 1972). Similarly, Janelle S. Taylor in Consuming Motherhood (2004) considers consumption and its allied forces as seminal in shaping lived experiences of mothers today, and hence endorses:

... ethnographic and historical explorations of how ordinary women, striving to build and maintain relations of kinship in the context of globalising consumer capitalism, live out motherhood in and through, as well as against, ideologies and practices of consumption' (2004: 12).

Taylor's research undertakes such a task analysing mothering, consumption and familial shifts in the context of social life across contemporary North America, as well as Europe, focussing on reproductive technology, the industry of 'care' and the overall consuming of such market driven 'goods' that make/unmake notions of motherhood.

Returning to Toril Moi's analysis of Bourdieu's discourse on materiality, gender and power, Moi cites Rogers Brubaker (1985) to explain Bourdieu's concept of 'class' as 'so distinct as to be applicable to any social group whose members share a certain number of material and social conditions and thus also develop' (1991: 1029). Moi understands this notion of 'class' as both a category of materiality and of gender, applicable to relationships constituted by the dominant and the dominated. Gender, for most feminists, is a superimposition of socially produced power relations between the sexes' onto embodied lives (Moi, 1991: 1030). Furthermore, the category of 'Woman' in this framework, 'is neither an essence nor an indeterminate set of fluctuating signifiers, but an arbitrarily imposed definition with real social effects' (1991: 1033). This 'natural' division is established as unquestionable, and becomes part of what Bourdieu terms as doxa or common knowledge/philosophy that keeps power relations intact (Bourdieu, 1990). A further addition to the understanding of such classes and power dynamics is the concept of symbolic violence, through which Bourdieu explains dominance within class structures. This form of violence is camouflaged, 'soft', naturalised and resorted to when direct violence is difficult to exercise. Significantly, symbolic violence becomes part of direct/indirect practices that women themselves perform, and in turn, sustain their dominated status within a social field.

Bourdieu's concept of the field (1996) is perhaps most crucial of all, as it provides a site for the play of power relations, class practices, censorship, conformity and most vitally, of symbolic violence and symbolic capital. Elucidating Bourdieu's notion of the 'field' in his seminal work Distinction (1996), Toril Moi writes:

... a field is a particular structure of distribution of a specific kind of capital. The right to speak, legitimacy, is invested in those agents recognized by the field as powerful possessors of capital ... in the very act of engaging in battle, they mutually and silently demonstrate their recognition of the rules of the game ... The different positions of different players in the field will require different strategies. ... Legitimacy (or distinction) is only truly achieved when it is no longer possible to tell whether dominance has been achieved as a result of distinction or whether in fact the dominant agent simply appears to be distinguished because he (more rarely she) is dominant.... (1991: 1022-1023).

Bourdieu himself attributes the 'structure of the field' to the essentially unequal way in which capital is distributed, leading to the appropriation of power and rules pertaining to the functioning of the field in the hands of those with a greater amount of capital. Additionally, such rules and laws are also formulated to further the cycle of capital and its reproduction. (Bourdieu, 1986: 284). Moi also stresses the heterogeneity of agents in the field and on their variegated economic, social and geographical backgrounds. However, the appropriation of Bourdieu by 
Moi is best reflected in her feminist critical self-reflexivity within the Bordieuan framework. Showing how feminist philosophers like Simone de Beauvoir were themselves a part of the construction of womanhood, while critiquing it, Moi declares that 'the would-be critic of the doxa [also] finds herself obliged to reflect on the conditions which produce her as a speaker”, (1991: 1028), alluding to the self-reflexivity required by socialist feminist analysis.

\section{MOTHERING, CONSUMPTION AND THE MALL-GOER}

Stephanie O'Donohoe and others (2013) bring together critical studies on different aspects of mothering today, including ideologies of mothering, tropes and performances of mothering, as well as shifts in 'doing' mothering, to the backdrop of global market forces and an intensifying material culture under global neoliberalism. Alison Clarke's article (Clarke in O’Donohoe 2013) explores the way social classes, market forces, media and motherhood stereotypes have influenced and alter each other. Clarke studies the way images of the perfect mother have metamorphosed into the symbol of the 'consumptive mother', who draws her identity from commodities, fashion and lifestyle choices available. Clarke calls this nexus of materiality as 'the cosmology of goods and taste knowledges' (2013: 5). The present discussion similarly positions women both as users of consumer products (at the simplest levels), besides producing their own complex 'products', including mothering. What Bourdieu calls 'the whole universe of life-styles' (1996: 176) also finds parallels in Harman and Cappellini's article which argues for example that 'lunchboxes are understood as an artefact linking together discourses and practices of doing and displaying mothering', with mothers revealing anxieties of being 'on display' via the food they packed. (2015: 764).

The DLF Promenade Mall, Delhi, becomes an example of consumer spaces driven by women. The research team visually registered the presence of mothers in different roles and age groups at the Mall from mothers accompanying their school children to food courts at the Mall, to young mothers visiting the Mall with toddlers and infants, to middle-aged women undertaking 'serious' shopping accompanied by young daughters at the mall. It must be reiterated that the Promenade Mall has established itself as a place catering to the shopping and lifestyle practices of the middle and upper middle classes of the national capital. Incorporating wellness spas, nail-art studios, food-courts, and even a play arena for children called 'Kiddyland', the Mall is marketed as a leisure destination, rather than just another retail hub. Without claiming to provide a comprehensive, or conclusive picture of mothering practises in the retail space, we observed: (i) the consuming practices undertaken by mothers that seem to challenge and complicate traditional notions of 'doing' mothering (ii) projects of self-transformation via the mall's amenities that seem to take consumption beyond motherhood, and (iii) and how in performing consuming motherhoods, these mothers imbibe and display a sense of taste or judgement (Bourdieu, 1996), which establishes them as conscious/unconscious agents and producers of the wave of hyper-consumption. The Mall symbolises promises of the 'cosmology of goods and taste knowledges' (Clarke, 2013: 5).

\section{Consumptive Practices and 'Doing' Mothering at the Mall}

The photograph in Figure 1 was taken in the play-area at the Promenade Mall called 'Kiddyland'. The arena boasts of a range of outdoor sports, slides and games on offer for children from preschool to around pre-secondary school age brackets. In the photograph, a young father is seen capturing his son's photograph, as the latter enjoys a slide at Kiddyland. Our interview with the father revealed that he was 'baby-sitting' his son, while his wife was finishing shopping in the shop outlets at the Promenade. The man also shared that as a nuclear family living in the city, the family undertook this routine quite often, where his wife would be free to shop, while he attended to the son playing in the arena. The availability of such amenities for play and relaxation (on a paid basis), was in fact, highlighted by the father as a crucial reason for their 'love' for this particular Mall. 


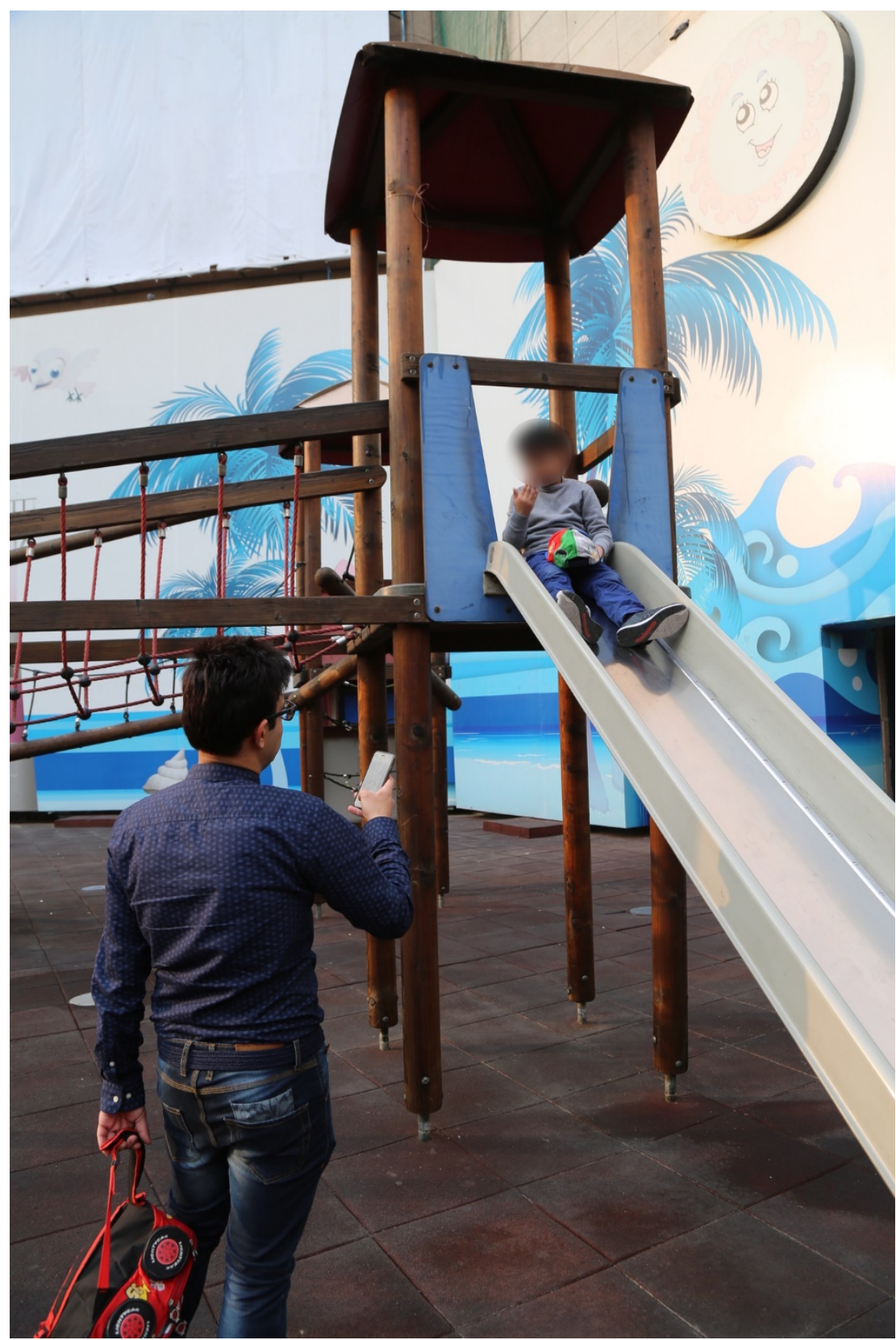

Figure 1. Father and Son duo at the Promenade

The research team spotted several young mothers at the Promenade Mall accessing the mall with infants. The photographs in Figures 2 and 3 document some of these mothers as they indulged in eating with family at food court, or strolled about in the company of other young mothers. The young mother photographed at the food court was accompanied by her parents-in-law, as well as a nanny for care of the infant. We traced the nanny seated on a separate table, eating by herself. In her interview with us, the young mother shared that visiting the Mall with her family for socialising and eating was one of her favourite activities, underlining that motherhood had not hindered her mobility and enjoyment through such spaces. The food court was also a popular location with school students who were seen at the Mall frequently. They were also often accompanied by their mothers to the food court. 'Hanging out' in the food court, and 'eating together' in such public spaces appeared to have become a regular practice with such mother-children groups, although it is notable that for the mother to enjoy herself, her labour was shifted onto a servant class. In addition to casually eating together (without the servants), the Mall also seemed to cater to intimate birthday celebrations hosted by mothers for their children, often attended by school mates/friends, and their mothers. 


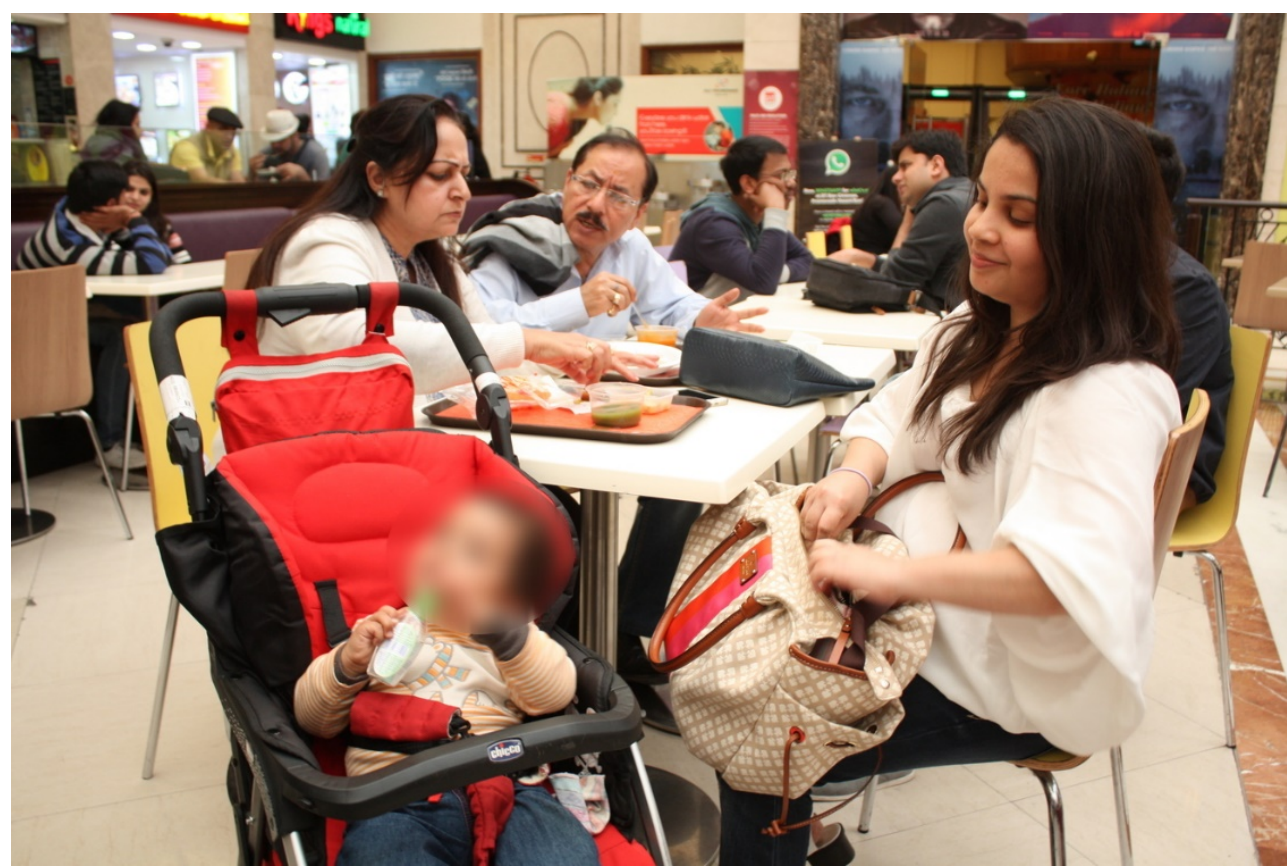

Figure 2. Young Mothers at the Promenade Mall

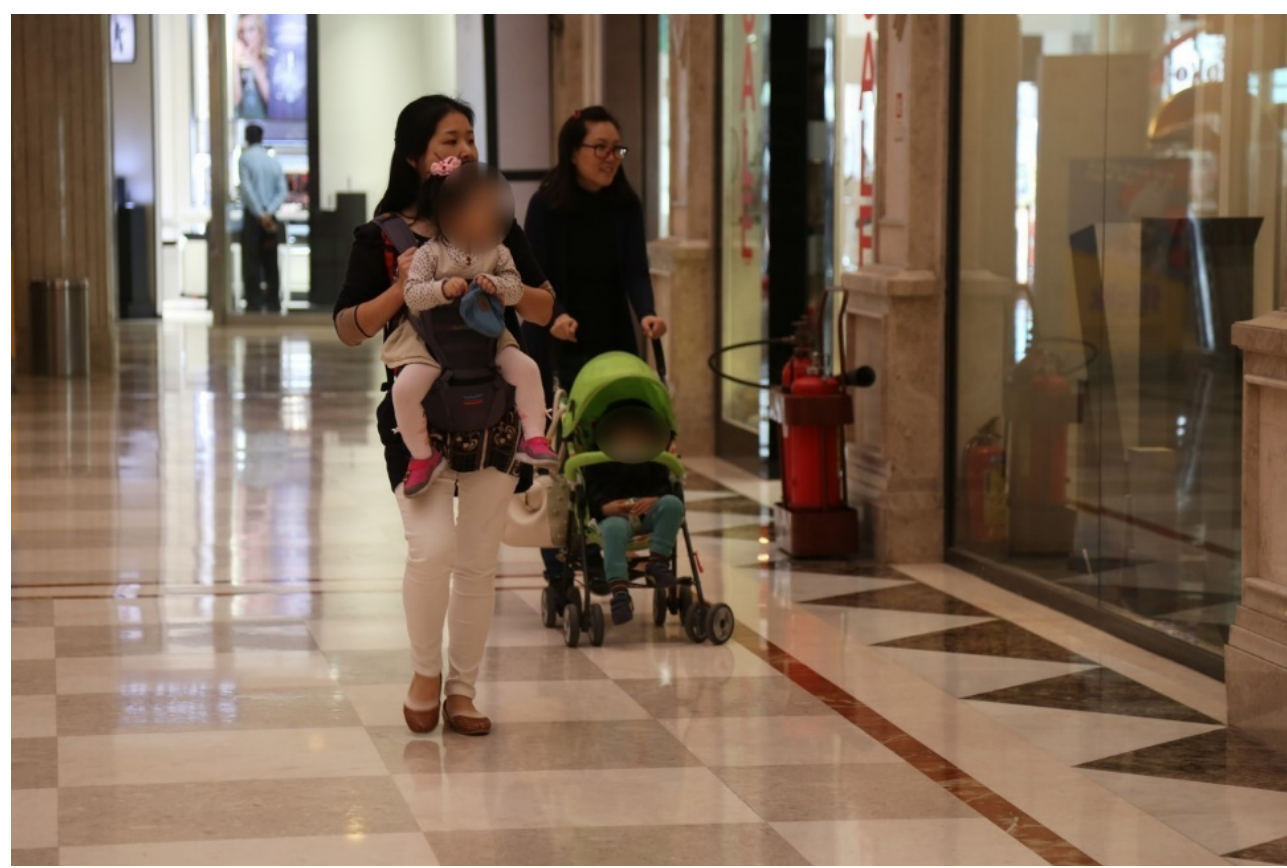

Figure 3. Young Mothers at the Promenade Mall

Craig Martin's research study (2009), offers data on children, their socialisation and consumptive habits derived from malls, and on American mother-daughter duos shopping together (see Figure 4). Martin points out how exposure to malls has emerged as a vital part of growing up for children, some of whom list 'going shopping' as their second favourite after-school leisure activity. Research from 30 years ago also referred to this trend( Schulman and Clancy, 1992), while underlining how children as young as age 10 can experience an average of 250 shopping expeditions annually (Dotson and Hyatt, 1994; Martin, 2009: 50).

The implications of performing such personal, familial celebrations as birthdays, 'get-togethers', and intimate bonding with parent in public arenas of the Mall, are complex, research into the material practices of mothering appear to challenge some of the most idealised conceptualisations of the role. Taylor et al argued back in 2004 that the merger of money and affection in the domain of mothering seems to arouse cultural anxieties, due to traditional perceptions of motherhood as a bond 'uniquely free of the kind of calculating instrumentality associated with the consumption of objects', as well as standing 'in opposition to the logic of the marketplace' (2004:3). The establishment of polemical values such as 'love' vis-à-vis 'money', 'care' vis-à-vis 'self-care' continue to be prevalent in cultural practices in India, where criticism of the material practices of 'modern' mothers by elderly women is 


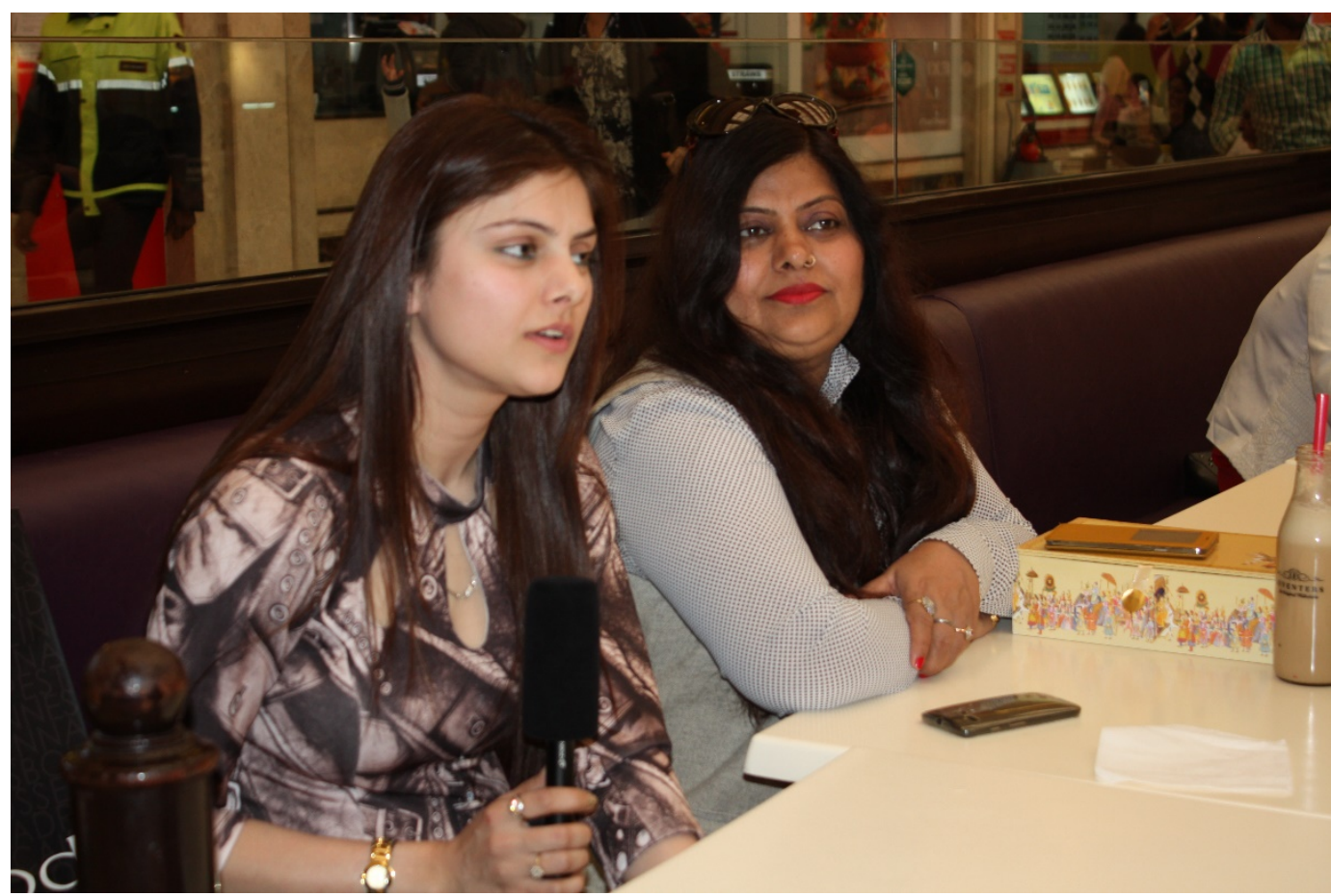

Figure 4. Mother-Daughter duo at the Promenade Mall

commonplace, especially within families. Traditionally, motherhood on the Indian sub-continent is a sacrosanct role women are expected to perform purely and sincerely.

\section{Makeovers at Malls: Beyond Mothering}

A number of women, especially middle-aged shoppers, preferred visiting the Promenade with their young daughters. The photo included above captures the semi-structured interview with a mother-daughter duo at the Mall. The mother introduced herself as a home-maker, while the daughter was a dentist. What struck the researchers about the duo were the similarities in their attire, make-up, and other markers of fashion, despite significant differences in age, education, articulation and the apparent body language of the mother and daughter. Though camera-shy, and uncertain of her English skills, the mother appeared to share the shopping and grooming choices of her daughter. The duo professed their love for high-street brands, and for frequent, 'serious' shopping trips to the Promenade, preferences that were corroborated by their groomed appearances, 'natural' make-up and attire. Relaxing at the Mall was also emphasised as a favourite activity by the duo. It remained difficult to ascertain whether the mother's aspirations had been manifested in the daughter's professional success. In examining social classes, gendered consumption and clothing, Bourdieu writes:

Among women, who, in all categories (except farmers and farm labourers), spend more than men (especially in the junior and senior executive, professional and other high-income categories), the number of purchases increases as one moves up the social hierarchy; the difference is greatest for suits and costumes--expensive garments (...) (1996: 201).

Though Bourdieu's analysis focuses on garments and choices specific to French society that may not find direct parallels in the Indian context today, his observations find parallels in the mother-daughter duo at the Mall who positioned themselves as consumers and products of global market forces and brands. In doing so, the mother and daughter also became emblematic of a particular aspirational social class. A considerable number of Mall amenities and retail strategies, were in fact formulated to appeal to the self-transformatising zeal of middle-aged mothers, keen to match their confident, younger daughters. 


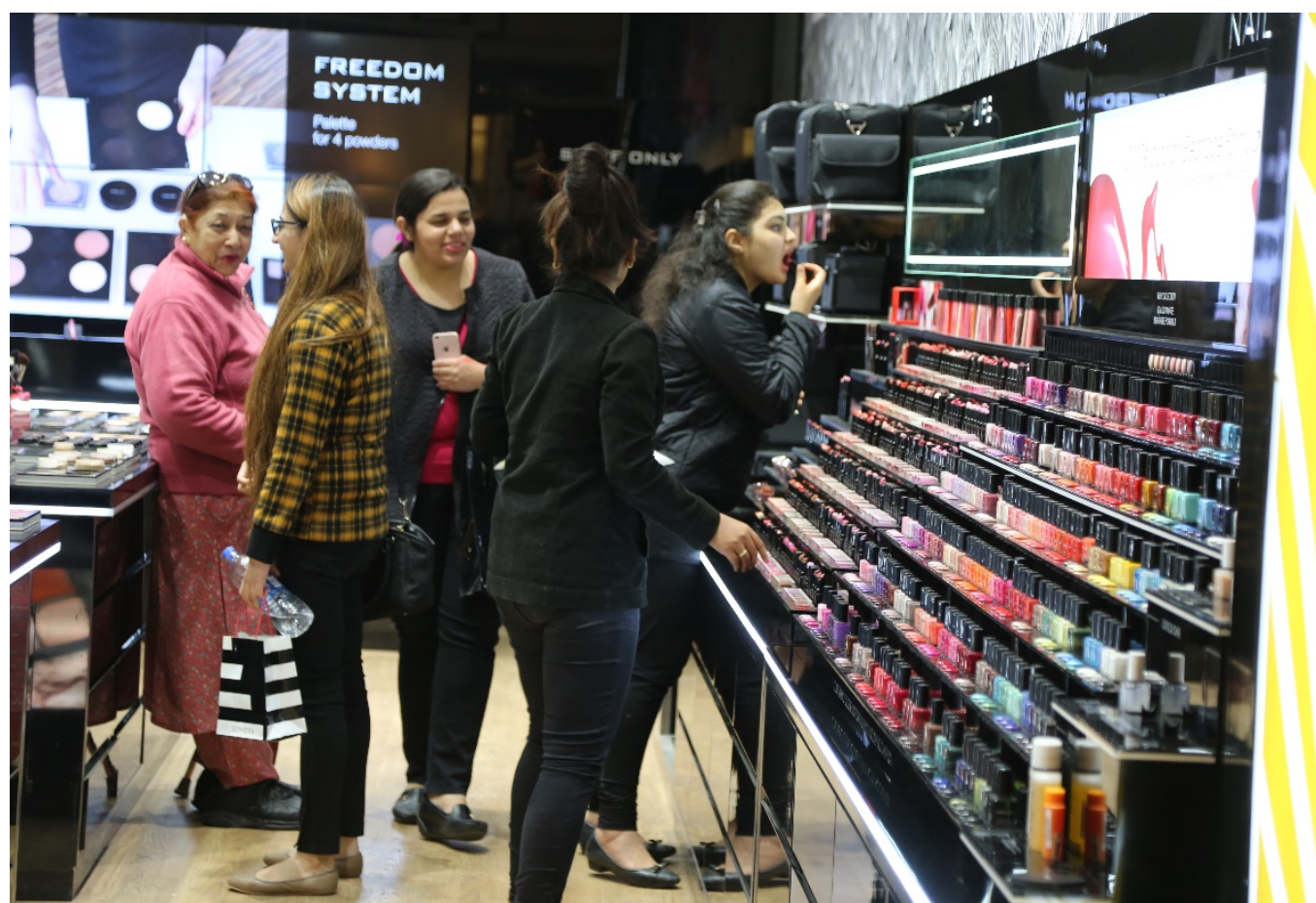

Figure 5. Makeovers and Nail Art at the Promenade Mall

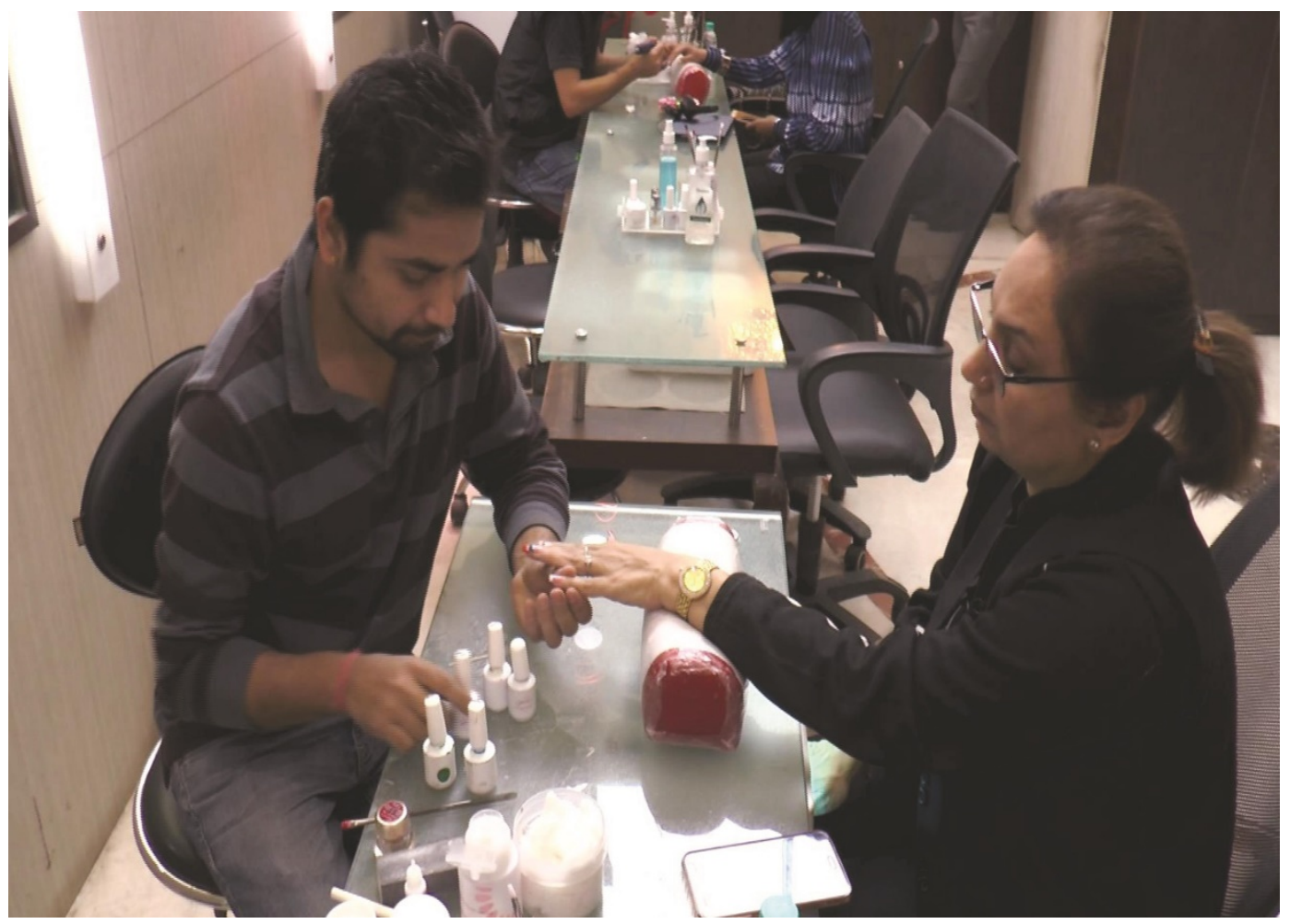

Figure 6. Nail-art at the Promenade Mall

The makeover sessions available at cosmetic stores, and health and beauty amenities such as wellness spas and nail art studio especially attracted the dedicated middle-aged mall-goer, aspiring to transform herself (see Figures 5 and 6). Significantly, while many of these mothers were accompanied by their young daughters, the realm of grooming, self-care and ultimate transformation undertaken within the mall seemed to have reversed parenting grooming roles between mothers and daughters. The daughters in such projects became both companions and motivations of a fashionable metamorphosis. Commodities at the Promenade Mall also catered for young and expectant mothers, facilitating their modern roles as working professionals, smart spouses and newage mothers. The urban clothing brand ' $\mathrm{W}$ ', we were told by salespeople, had introduced a line of trousers and other formal clothing for expectant mothers employed in corporate and business establishments, while the quality 
British maternity brand 'Mothercare' had recently launched front-opening bras for lactating mothers, a product not available in the country before.

\section{Yummy Mummies, 'Taste' and Symbolic Capital}

Bourdieu identifies 'taste' or 'judgement' as 'the heavy artillery of symbolic violence' (1026), through which dominant classes naturalise control and reinforce power. The logical extension of this violence occurs in a stage in which the dominated adopts the taste and distinction of the dominant in a reproduction of dominant cultural values. Cultural capital (education), social capital (familial and social goodwill), and economic capital, all contribute to the establishment of such 'taste' behaviours, which in turn may lead to the generation of symbolic capital and symbolic violence. An understanding of Bourdieu's ideas on taste is critical for studying how preference for elite brands, 'taste' for fine dining/healthy food, indulgence in expensive spas and nail studios constitute the markers of those of the dominant class, whilst naturalising and furthering their control on such neoliberal spaces. Hence, to be visible in an exotic spa is a sign of economic capital and 'taste' through practices of exclusivity while accessing the spa is dependent on the precondition of being wealthy. The deepening of social stratifications, exclusionary practices and symbolic violence generated via the mall are further explored by investigating the 'Other' of such consumptive arenas- the migrant labour that underpins the Promenade Mall and its practices of mothering.

\section{THE ‘OTHER’ MOTHERS: MIGRANT EMPLOYEES AND ASPIRATIONS}

In an attempt to study the influence of neo-liberal spaces such as malls on different social classes the research team conducted semi-structured interviews and focus group discussion with mall employees working as security and housekeeping personnel. The team also visited the ghettoes in which these migrant workers lived, interacting with their families as well. The subsequent section of this paper attempts to record how migrant mothers in the mall social research field negotiated the unequal distribution of various capitals within and beyond the physical domain of the Promenade Mall. The analysis seeks to understand the ways in which consumptive practices of mallgoing mothers also propel aspirational projects of the migrant mothers working at the Promenade. The discussion focuses on the problematic aspects of such a commercial space, which on the one hand furthers dreams of urban living, employment and the acquisition of varied forms of capital, and on the other, leads to the inequality traps of market forces, consumption, and above all, of promoting the very doxa that contributes to the oppression of dominated classes and their exploited labour.

Toril Moi articulates a feminist understanding of the internalisation of social and consumer roles. Elaborating Bourdieu's conceptualisations on the subordination of minorities, Moi writes:

A feminist analysis of the impact of gender on a woman's discourse and consciousness must also bear
in mind that to be a member of a disadvantaged minority within a given institution or field in no way
guarantees that one will develop a revolutionary or oppositional consciousness. On the contrary:
ostensibly egalitarian institutions tend to breed consent rather than opposition, particularly among the
miraculis - the miraculous exceptions. For the paradox is that members of minority groups who do
succeed in such a system are at least as likely to identify with it as the enabling cause of their own success
as to turn against its unjust distribution of symbolic capital (1991: 1037).

Moi further explains that while 'femaleness' might generate 'negative capital' in the class stratifications based on gender hierarchies, in the economic stratifications of class, this 'negative capital' might be balanced by the possession of other forms of capital (such as cultural and symbolic capital). Thus, within a given field, power relations between women as mothers, depend on a diverse set of factors, including their internalising of the motherfunction, the distribution of a particular form of capital unequally in the specific field they are occupying, as well as women's overall possession of other forms of capital in different measures. Our article undertakes an examination of the paradoxical ways in which the migrant mothers employed in the Promenade seek to socially 'progress' by gaining inspiration from mothers of the middle and upper middle classes frequenting the Mall as consumers. This aspirational project of upward mobility, capital generation, and overall 'progress' implicates women in promoting the doxa that arguably furthers their subordination, and becomes manifest most clearly in the migrant mother's failed attempts at bourgeois embodiment in her transformation, grooming and change for the self and her practices of mothering dedicated towards children.

The DLF Promenade has attracted migrant workers from different states of India. The Promenade Mall's dayto-day functioning is dependent on a 500-600 member workforce that is constituted by a majority (90\%) of internal (to India) migrants. Primarily working for the security and housekeeping teams of the Mall, these migrant workers belong to states of Rajasthan, Haryana, Uttar Pradesh, Bihar, Jharkhand, West Bengal, Madhya Pradesh, Orissa, among others. Most of these migrant workers are women who had left their home-states with their spouses, or in 


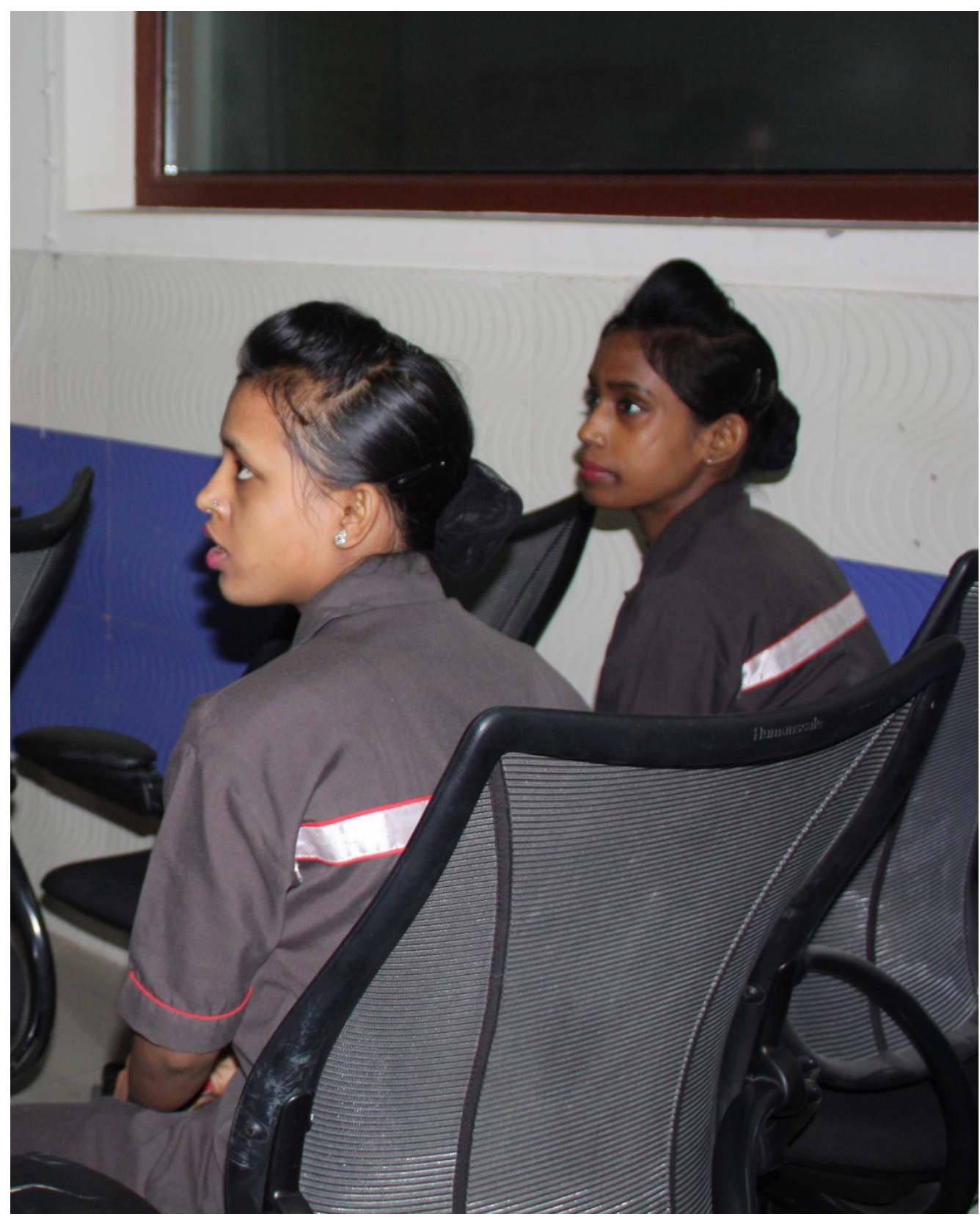

Figure 7. Housekeeping Staff with 'Puff' Hairstyles

a few cases with their brothers or families. A majority of them were already mothers, while the remaining aspired to be mothers as soon as they would be 'well-settled'. Employment at the mall fetched them a salary of around INR 8,000, one weekly off day, and a more symbolic 'respectability', a term almost all of them used to answer questions on why they wanted to work at a shopping mall. Though not the most lucrative job, work at the mall was definitely perceived by these women as a sign of their 'progress' in social strata, especially when they compared it to their earlier roles as domestic help, servants, shop workers and the like. They argued that employment at the Promenade had opened vistas to them of multiple kinds. Having migrated from poor villages and semi-urban towns, the sanitised, air-conditioned and well-secured premises of the Mall represented improved working conditions to these women. The majority of migrant women claimed they had never been to a mall before, but now aspired to shop and eat at such places, particularly with their children, so the workforce aspired to be consumers themselves.

Entry into the Mall had altered the lives of these mothers, especially in terms of appearance, grooming, and body language. Such alterations were also essential to the nature of their job that required qualities such as a 'presentable' exterior and 'warm' demeanour (as commented upon by the woman-supervisor of the housekeeping team). It was striking that women working in the capacity of housekeeping staff and security personnel were required to use 'light make up' that included lip colour. The housekeeping staff had in fact received training in applying such makeup, and creating a specific hairstyle - the 'puff' (See Figure 7). This kind of expectation of 
appropriate, conforming femininity is of course a required performance of much employment by women in service industries.

A number of mothers among these mall workers, expressed their awe towards women visitors of the mall particularly their mannerisms, groomed appearances, and the ease with which the middle and upper middle class women accessed and 'belonged' to the Mall, their embodied capital as a classed performance. Asha (name changed) from the village of Hardoi, Uttar Pradesh worked as housekeeping staff and spoke of how mothers visiting the mall would spend a considerable amount of time in restrooms providing final touches to their make-up. Asha found such habits fascinating, while pointing out that such mothers did not appreciate housekeeping staff playing or fondling their children, even as the Mall-going mothers were busy putting their look together in the sanitised restrooms. Asha also shared her own gradual liking for a well-put appearance on her outings, she articulated her own desire to buy clothes, while admitting that the she could wear 'pants' only at the Promenade Mall and never at home with her family. The joy of observing 'smart' women visiting the Mall, the ubiquitous spread of attractive commodities, and the overall respect she gained from her work, made Asha perceive the Promenade Mall as a liberating space. Similarly, Radha (name changed) hailing from Bakshi-ka-Talab, a village near Lucknow, Uttar Pradesh and employed as a member of housekeeping staff at the Promenade, spoke of her expenses such as providing clothes for her children. On being asked about their consumption practices and recreational activities, the majority of these women mentioned shopping as a favourite activity, with the humble disclaimer of the fact that they could not afford this mall, but instead visited cheaper wholesale outlets.

Bourdieu in his writing assigns considerable importance to 'the inscription of social power relations on the body', as part of the 'Bildung' or education that promises power and change (as discussed by Moi, 1991: 1030). Such inscriptions include 'movements, gestures, facial expressions, manners, ways of walking, and ways of looking at the world' (1991: 1031). In the case of these mothers, this cultural education becomes critical to 'doing' mothering, and entails 'activities [such] as teaching children how to move, dress, and eat' (1031), in order to attain legitimacy within the field. As Moi states: 'The body-and its apparel such as clothing, gestures, make-up and so onbecomes a kind of constant reminder (...) of sociosexual power relations' (1991: 1031). Such an understanding of obtaining legitimacy through the bodily corroborates the seminal role that mothering plays in shaping 'Bildung' in a field, especially in the context of these Indian migrant mothers. Semi-structured interviews with such mothers working at the mall, indicated the extraordinarily aspirational nature of their schemes, largely derived from their interaction with consumer forces at the mall. Keen to uncover the complex components of mothering being undertaken by these migrant mothers, the team was given permission to visit their homes and localities. In the following sections, the lifestyle and consumptive practices of Radha are analysed in detail.

Like most migrant workers of the Promenade Mall, Radha lived with her husband and two children in one of the urban villages close to the Mall. These villages included areas known for catering to migrants descending on the national capital for employment, such as Masoodpur, Harijan Basti (roughly translated as Ghetto of the Untouchables), Mahipalpur, to name a few (see Figure 8). These ghettos stood in sharp contrast to the global ambience and shiny amenities of the malls nearby. Signs of aspiration and the desire to move-up in the field were visible in the numerous banners of tailoring shops, cheap English-speaking coaching centres, and even contacts for procuring fake educational certificates in the migrants' locales. One also came across children returning from affordable, government-run schools, accompanied by mothers (carrying their children's school-bags) in neat sarees and measured, affordable, make-up. 


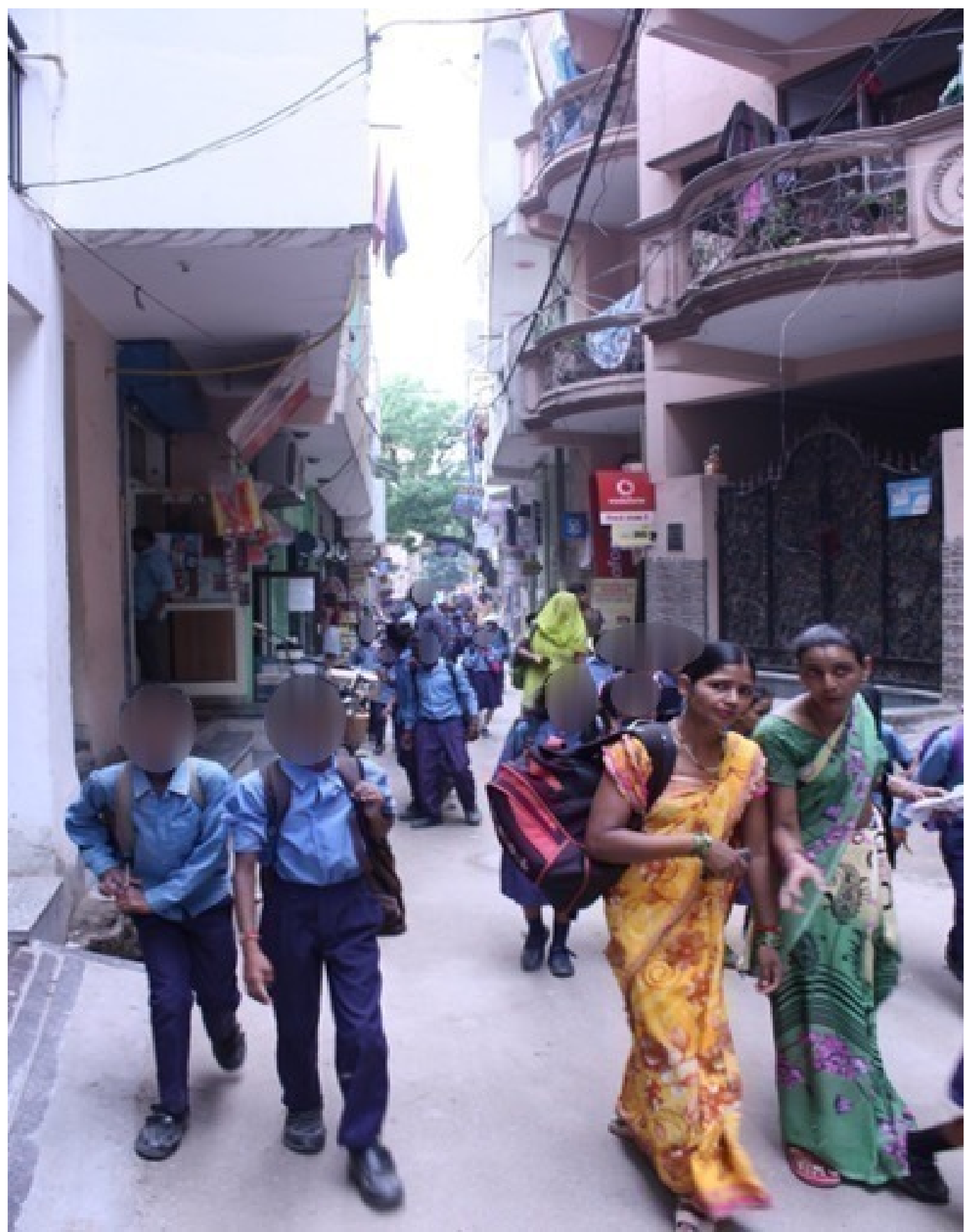

Figure 8. Scenes from a Ghetto near Vasant Kunj, Delhi

Radha's one-room home had no windows and was in darkness even in the afternoon when the team visited her (see Figure 9). She was dressed in traditional salwar-kameez, unlike in her westernized trouser and shirt at the Promenade. However, she had still kept the 'light-make up' intact, wearing it comfortably as a part of her persona, even in the strikingly different modest surroundings of her home. The huge building had ten rooms such as Radha's on each floor which are rented to individual families, and a common toilet and a bath. On being asked about the glittery streamers that beamed on a wall in the dark room, Radha smiled and shared that they were part of the décor for her son's birthday-celebrations held a few months ago.

Initially shy, Radha gradually opened up during the interview, revealing that her family belonged to the Dalit 1 community. This meant that they had never been treated with respect and equality at their village in Uttar Pradesh. Her relationship with her husband (also employed in a nearby mall) had also been abusive, and had remained so even after the birth of her children. Working at the Promenade Mall, according to Radha, provided her with an opportunity to gain dignity, financial independence, and a new lifestyle in an urban centre, far removed from the oppressive structures of the caste system in her village. Radha spoke of her desire to save up money and 'do things'

${ }^{1}$ Dalit, meaning 'untouchable' or 'broken' in Sanskrit, is a term associated with the oppressed sections of the Indian social class. The Dalits have been traditionally seen as the lowest people in the Hindu caste system. 


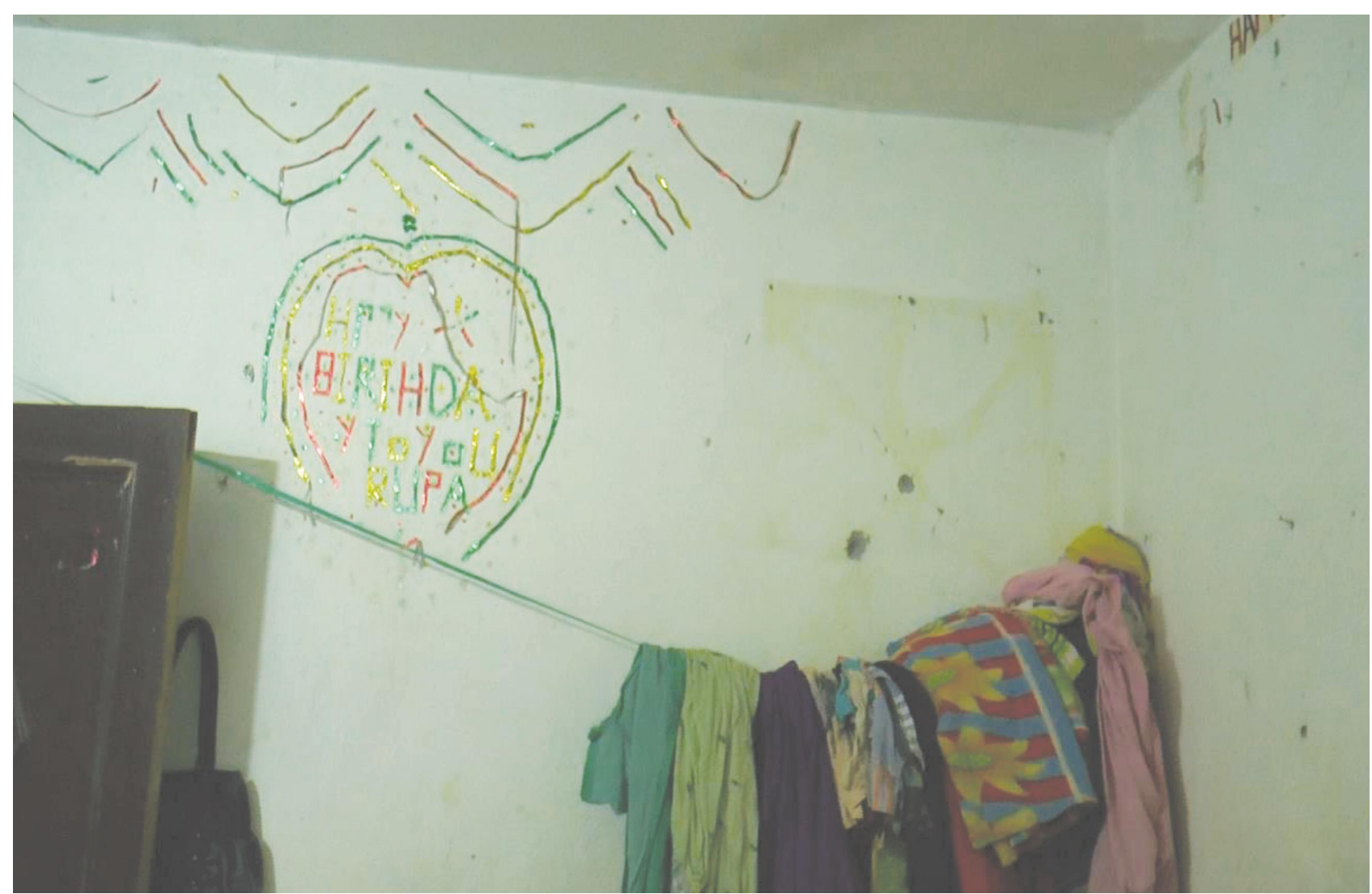

Figure 9. Interiors of Radha's home

in life. This crucially included the education of her children. She had admitted her daughter to a nearby school and had even enrolled her for private tuitions at high cost, to boost her daughter's prospects of gaining education and her social mobility. Radha viewed these acts of mothering as integral to the project of gaining social legitimacy and material progress.

Explaining the paradox of the 'Bildung' project pursued by the dominated classes, Moi revisits Bourdieu to state:

The function of the educational system ... is above all to produce the necessary social belief in the legitimacy of currently dominant power structures, or in other words: to make us believe that our rulers are ruling us by virtue of their qualifications and achievements rather than by virtue of their noble birth or connections. The coveted diploma or exam paper becomes a token of social magic, the emblem of a transformational exercise which truly changes the essence of the chosen elite (1991: 1023).

Bourdieu's elucidations of the 'Bildung' project, specifically its interconnections with education, 'care', consumption and an overall trajectory of aspiration, make it an apt emblem for the complex project of mothering and its social dynamics today. Our research study Mall: A Gendered Space threw up several vital revelations regarding gender and mothering, performed unceasingly within the mall space. A product and bearer of neoliberal values, the Promenade Mall appeared to provide emboldening prospects to mothers accessing it: whether as consumers or as migrant employees. While new lifestyle practices, display of 'taste' and possibilities of self-transformation implicated mothers as pampered consumers of such arenas, the unequal distribution of capital in all its forms, also made them agents of symbolic violence onto another and lower class of women. The migrant mothers working at the Promenade emerged as conscious agents aspiring for change, through material performances of mothering - a fact that implicated them further in the traps of the regulatory and traditionally gendered mother-function. Together, both types of mothers appeared to be consciously/unconsciously endorsing the very 'doxa' that ensured their sustained gender subordination in and across different fields, even as they pursued the project of change through retail markets and complex forms of consumption. As part of our feminist methodology and ethics, the research team signed out of the Promenade project by requesting the mall's management to provide feeding-areas for the young mothers accessing the mall (a suggestion that was briskly implemented). It also met with Radha again, offering her help/encouragement for approaching women's forum to report domestic abuse.

Note: All Images used are captured by the Institute of Studies in Industrial Development, Delhi (ISID). Copyrights are shared by the ISID and the Women's Studies and Development Centre, University of Delhi. 


\section{REFERENCES}

Afflerback, S., Anthony, A. K., Carter, S. K. and Grauerholz, L. (2014). Consumption rituals in the transition to motherhood. Gender Issues, 31(1), 1-20. https:/ / doi.org/10.1007/s12147-014-9115-0

Barthes, R. (1972). Mythologies (Trans. by A. Lavers). New York, Farrar, Straus \& Giroux: The Noonday Press.

Biyani, K. and Baishya, D (2007). It Happened in India. New Delhi: Rupa.

Bourdieu, P. (1977). Outline of a Theory of Practice (Trans. by R. Nice). Cambridge: Cambridge University Press. https://doi.org/10.1017/CBO9780511812507

Bourdieu, P. (1986). The forms of capital. In J. Richardson (ed.) Handbook of Theory and Research for the Sociology of Education (pp. 241-58). Westport, CT: Greenwood.

Bourdieu, P. (1996). Distinction: A Social Critique of the Judgement of Taste (Trans. by R. Nice). Cambridge, Massachusetts: Harvard University Press.

Bourdieu, P. (1996). Physical Space, Social Space and Habitus. Oslo: University of Oslo.

Brubaker, R. (1985). Rethinking classical theory: the sociological vision of Pierre Bourdieu. Theory and Society, 14, 745-75. https://doi.org/10.1007/BF00174049

Gooptu, N. (2009). Neoliberal subjectivity, enterprise culture and new workplaces: organised retail and shopping malls in India. Economic and Political Weekly, XLIV(22), 45-54.

Harman, V. and Cappellini, B. (2015). Lunchboxes, social class and moral accountability mothers on display: lunchboxes, social class and moral accountability. Sociology, 49(4), 764-781. https://doi.org/10.1177/0038038514559322

Hegel, G. W. F. (1977). Phenomenology of Spirit (Trans. by. A. V. Miller). Oxford, New York, Toronto, Melbourne: Oxford University Press.

Husserl, E. (1913). Ideas Pertaining to a Pure Phenomenology and to a Phenomenological Philosophy_First Book: General Introduction to a Pure Phenomenology. (Trans. by F. Kersten). The Hague, Boston, Lancaster: Martinus Nijhoff Publishers.

Kalpana, H. (2002). Gender, culture and space in the Shimla mall. Economic and Political Weekly, 37(25), 2403-2405.

Kawash, S. (2011). New directions in motherhood studies. Signs, 36(4), 969-1003. https://doi.org/10.1086/658637

Martin, C. A. (2009). Consumption motivation and perceptions of malls: a comparison of mothers and daughters. Journal of Marketing Theory and Practice, 17(1), 49-61. https://doi.org/10.2753/MTP1069-6679170104

Miller, D. (ed.) (2005). Materiality. Durham and London: Duke University Press. https://doi.org/10.1215/9780822386711

Moi, T. (1991). Appropriating Bourdieu: feminist theory and Pierre Bourdieu's sociology of culture. New Literary History, 22(4), 1017-1049. https:// doi.org/10.2307/469077

O’Reilly, A. (ed.). (2010). Twenty-first Century Motherhood: Experience, Identity, Policy, Agency. New York: Columbia University Press.

O’Donohoe, S., Hogg, M., Maclaran, P., Martens, L. and Stevens, L. (ed.) (2013). Motherboods, Markets and Consumption: The Making of Mothers in Contemporary Western Cultures. London and New York: Routledge. https://doi.org/10.4324/9780203469729

Phadke, S., Khan, S. and Ranade, S. (2011). Why Loiter? Women and Risk on Mumbai Streets. New Delhi: Penguin Books Pvt. Ltd.

Sen, S. (1993). Motherhood and mothercraft: gender and nationalism in Bengal. Gender \& History, 5(2), 231-243. https://doi.org/10.1111/j.1468-0424.1993.tb00174.x

Singh, H. and Srinivasan, S. R. (2012). Mall Management: Operating in Indian Retail Space. Noida: Tata McGraw Hill Education Private Limited.

Taylor, J. S. and Layne, L. (ed.) (2004). Consuming Motherhood. New Brunswick: Rutgers University Press

Thapan, M. (1996). Understanding the anthropological method. Economic and Political Weekly, 31(38), 2631.

Voyce, M. (2007). Shopping malls in India: new social 'dividing practices'. Economic and Political Weekly, 42(22), 2055-2062.

Zahavi, D. and Overgaard, S. (2013). Intersubjectivity. https://doi.org/10.1002/9781444367072.wbiee274

Citation: Tewari, R. and Bhatia, M. (2019). 'Mothers at the Malls': A Study of Glocal Aspirations and Mothering from Delhi. Feminist Encounters: A Journal of Critical Studies in Culture and Politics, 3(1-2), 14. https://doi.org/10.20897/femenc/5920 